\title{
Computational Tuning of the Paddlewheel tcb-MOF Family for Advanced Methane Sorption
}

Mikhail Suyetin, Maxim V. Peskov, Udo Schwingenschlög1*

King Abdullah University of Science and Technology (KAUST), Physical Science and Engineering Division (PSE), Thuwal 23955-6900, Saudi Arabia

\begin{abstract}
A series of metal-organic frameworks (MOFs) with tcb net topology and linkers of increasing size (combining triple bonds and benzene rings) is computationally designed using molecular mechanics and density functional theory. By grand canonical Monte Carlo simulations, we identify MOFs with outstanding methane total uptakes and working capacities, satisfying the targets of the US Department of Energy for automobile applications in cold weather regions $\left(50 \mathrm{wt} \%, 263 \mathrm{~cm}^{3}(\mathrm{STP}) \mathrm{cm}^{-3}\right)$. For example, the 5B MOF achieves at $298 \mathrm{~K}$ working capacities of $52.2 \mathrm{wt} \%$ at 5-65 bar and $61.9 \mathrm{wt} \%$ at 5-80 bar. The 3B MOF exhibits at $298 \mathrm{~K}$ the most balanced (gravimetric vs. volumetric) total uptake and working capacity in the family of tcb-MOFs: $28.4 \mathrm{wt} \%, 160.9 \mathrm{~cm}^{3}(\mathrm{STP}) \mathrm{cm}^{-3}$ at 35 bar and $23.0 \mathrm{wt} \%, 130.3 \mathrm{~cm}^{3}(\mathrm{STP}) \mathrm{cm}^{-3}$ at 5-35 bar (exceeding the benchmarks of rht-MOF-7, IRMOF-6, IRMOF-9, PCN-14, Ni-MOF-74, Al-soc-MOF-1, MOF-205), $38.4 \mathrm{wt} \%, 218.0 \mathrm{~cm}^{3}(\mathrm{STP}) \mathrm{cm}^{-3}$ at 65 bar and $33.0 \mathrm{wt} \%, 187.5$ $\mathrm{cm}^{3}(\mathrm{STP}) \mathrm{cm}^{-3}$ at 5-65 bar (exceeding the benchmarks of IRMOF-6, PCN-14, Ni-MOF-74, HKUST-1, NU-111, NOTT-101a), $41.6 \mathrm{wt} \%, 235.9 \mathrm{~cm}^{3}(\mathrm{STP}) \mathrm{cm}^{-3}$ at 80 bar and $36.2 \mathrm{wt} \%, 205.3 \mathrm{~cm}^{3}(\mathrm{STP}) \mathrm{cm}^{-3}$ at $5-80 \mathrm{bar}$ (exceeding the benchmarks of Ni-MOF-74, MOF-5, MOF-205, HKUST-1).
\end{abstract}

Keywords: methane storage, metal-organic framework, material design, molecular mechanics, density functional theory, Monte Carlo

*Email: Udo.Schwingenschlogl@kaust.edu.sa 


\section{Introduction}

Metal-organic frameworks (MOFs) are crystalline materials ${ }^{1,2}$ with unique properties exploited in a range of applications: light harvesting ${ }^{3,4}$, drug delivery ${ }^{5}$, biomedical imaging ${ }^{6}$, catalysis ${ }^{7-9}$, and gas separation and storage ${ }^{10-}$ 19. Their porosity combined with an easy tunability of the pore size results in outstanding potential in natural gas storage for automobile applications. Natural gas is superior to gasoline or diesel due to dramatically reduced release of dangerous pollutants such as $\mathrm{NO}_{\mathrm{x}}, \mathrm{SO}_{\mathrm{x}}, \mathrm{CO}$, and $\mathrm{CO}_{2}{ }^{20}$. As natural gas consists mainly of methane, evaluating the methane total uptakes and working capacities of MOFs is of great interest. The latter is usually calculated as difference between the total uptake at a pressure of $35 \mathrm{bar}, 65 \mathrm{bar}$, or $80 \mathrm{bar}$ and that at a pressure of $5 \mathrm{bar}^{8}$. Both variants of the total uptake and working capacity, gravimetric and volumetric, are important for characterizing the effectiveness of the methane storage ${ }^{21,22}$. In 2009 the US Department of Energy (DoE) has announced targets for the methane storage in automobile applications: A gravimetric working capacity of $50 \mathrm{wt} \%$ and a volumetric working capacity of $350 \mathrm{~cm}^{3}(\mathrm{STP}) \mathrm{cm}^{-3}$ at $298 \mathrm{~K}^{23}$. The volumetric target takes into account the density of the adsorbent. Considering a 25\% reduction due to the fact that MOF crystallites are pressed into pellets with lower density than a single crystal, the target becomes $263 \mathrm{~cm}^{3}(\mathrm{STP}) \mathrm{cm}^{-3}$.

Due to advances in molecular simulations, modelling nowadays plays an invaluable role in predicting MOF structures and properties. Structure-property relationships can be obtained with high accuracy and much faster and cheaper than in real experiments ${ }^{24-28}$. Evaluation of different benchmarking materials has shown that classical force fields provide good agreement of the bulk modulus and linear thermal expansion coefficient with precise firstprinciples calculations ${ }^{29}$. The flexibility of MOFs has been studied based on the assumption that the framework consists of rigid elements connected by hinges ${ }^{30}$. Controlled release of methane molecules from Mg-MOF-74 by means of a molecular gate guided by an electric field has been predicted in Ref. 31 and a computational screening approach for MOF structure design from a library of chemical building blocks (of known compounds), with the target to enhance the methane working capacity, has been introduced in Ref. 32. A computational technique for evaluating structure-property relationships using algorithms from machine learning has been developed in Ref. 33, demonstrating fast and accurate identification of MOFs for efficient carbon dioxide storage $(\sim 300,000$ hypothetical MOFs generated by combining 66 secondary building units and 19 functional groups). Screening of more than 20,000 candidates has led to the conclusion that the volumetric hydrogen total uptake is maximal for MOFs with surface areas in the range of $3100-4800 \mathrm{~m}^{2} / \mathrm{g}^{34}$.

While it is difficult to achieve simultaneously both the gravimetric and volumetric US DoE targets for the methane working capacity, computational methods can point to new venues ${ }^{35}$. For example, the Materials Genome Initiative, 
a computational approach to screen databases, has been applied to nanoporous structures to identify limits for the methane working capacity ${ }^{24}$ and hydrogen total uptake ${ }^{36}$. Hypothetical frameworks have been proposed in Ref. 37 in order to minimize the framework density and maximize the void volume for methane molecules. The highest volumetric total uptake ( $80 \%$ of the US DoE target) has been found in the case of diamond-like networks. The properties of Al-soc-MOFs have been analyzed in Ref. 38 by a molecular simulation approach consisting of two steps, framework optimization on the molecular mechanics level of theory followed by evaluation of the working capacity. The results reveal a clear correlation between pore structure and methane storage properties: Shortening the linker leads to dramatic enhancement of the volumetric working capacity but lowers the gravimetric working capacity. In this work, molecular mechanics and first-principles approaches are employed to design a novel family of MOFs with tcb net topology (for which none of the known coordination polymers is interpenetrated) that satisfy the US DoE targets for automobile applications at low temperature and provide balanced methane total uptakes and working capacities.

\section{Computational details}

We analyze the topologies of paddlewheel coordination polymers by the TOPOS 4.0 Professional package ${ }^{39}$. The tcb net topology occurs in several coordination polymers with metal-N and metal-O bonds ${ }^{40-45}$ but has not been reported in coordination polymers with polynuclear secondary building units, such as the paddlewheel cluster ${ }^{46}$. The tcb net has orthorhombic symmetry with space group Pnna and incident edges forming an angle of $76.6^{\circ 47}$. As this geometry resembles the coordination figure of the metal atoms in the paddlewheel cluster, the tcb net is suitable for building new paddlewheel MOFs. There is only one type of vertex (uninodal net), i.e., the number of building units required to construct structures with tcb net is low, which is favorable both for design and synthesis. We build MOFs using the paddlewheel cluster and ditopic dicarboxylate linkers shown in Figure 1. All the linkers considered have been demonstrated to result in stable $\mathrm{MOFs}^{48-50}$. They are given names according to the number of triple bonds $(\mathbf{T})$ and benzene rings $(\mathbf{B})$ in the linker. Figure 2 shows the tcb net and the schematic structure of a MOF based on the paddlewheel cluster and the B linker. A paddlewheel cluster consists of two metal atoms linked by four bridging carboxylates. While paddlewheel clusters can be formed with various metals, resulting in different binding affinities, $\mathrm{Cu}$ is the most common choice and, at the same time, is available at low cost. For this reason, we consider $\mathrm{Cu}$ paddlewheel clusters. 


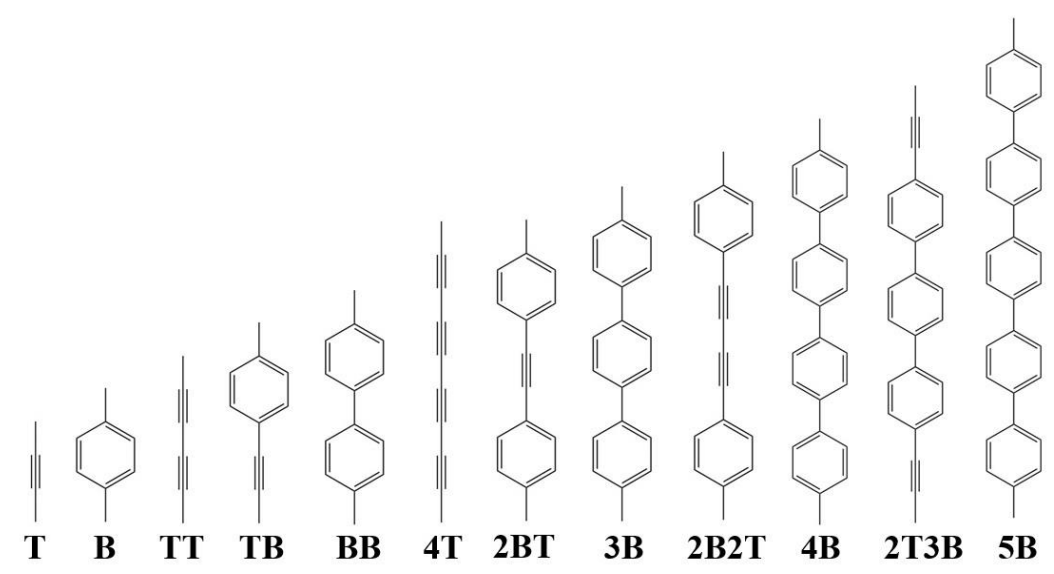

Figure 1. Organic linkers used to obtain a series of tcb-MOFs.

(a)

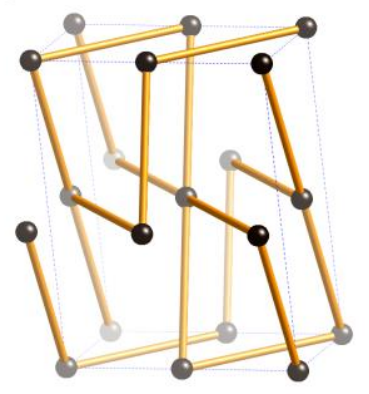

(b)

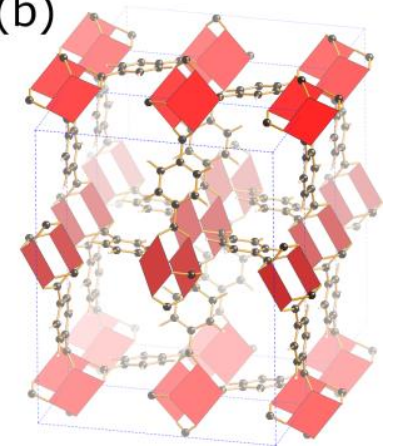

Figure 2. (a) Topology (tcb net) and (b) schematic structure of a MOF based on the paddlewheel cluster and the $\mathbf{B}$ linker.

The MOF structures are built by estimating the three lattice vectors, placing the paddlewheel clusters onto the vertices of the net, and connecting them by the linkers. The paddlewheel clusters are oriented to connect with the four nearest-neighbor linkers. The atomic coordinates then are optimized at constant unit cell parameters employing molecular mechanics. We use the Forcite ${ }^{51}$ software with the universal force-field ${ }^{52}$ for describing the strong covalent interactions. The Smart algorithm of Forcite is employed with convergence criteria of $10^{-4} \mathrm{kcal} / \mathrm{mol}$ for the energy, $5 \cdot 10^{-3} \mathrm{kcal} / \mathrm{mol} / \AA$ for the force, $5 \cdot 10^{-3} \mathrm{GPa}$ for the stress, and $5 \cdot 10^{-5} \AA$ for the atomic displacments. We verify the unit cell parameters by first-principles calculations (SIESTA ${ }^{53}$ software), using finite-range pseudoatomic orbitals (double- $\xi$ with polarization) in the basis and the generalized gradient approximation ${ }^{54}$. A fine realspace grid is employed, defined by an energy cutoff of $600 \mathrm{Ry}$. The atomic positions are optimized by the conjugate gradient algorithm until the Hellmann-Feynman forces are converged to $0.01 \mathrm{eV} / \AA$. A series of calculations is performed for the B MOF with different unit cell parameters, changing the unit cell volume by up to 5\%. The obtained energies are fitted to the Birch-Murnaghan equation of state ${ }^{55}$ in order to find the volume that minimizes the total energy. The equilibrium volume is determined by optimizing the b/a and c/a ratios. We find excellent agreement of the results with those from molecular mechanics. For this reason, the unit cell parameters of 
the other eleven predicted MOFs are optimized by molecular mechanics only (adopting a convergence criterion of $0.01 \AA$ for the maximal change in the unit cell parameters).

Grand canonical Monte Carlo simulations are used for investigating the methane total uptake and working capacity (gravimetric and volumetric) at different temperatures ( $240 \mathrm{~K}, 258 \mathrm{~K}, 273 \mathrm{~K}$, and $298 \mathrm{~K}$ ) and pressures (up to 90 bar). The methane molecule is treated as united atom, with parameters taken from the TRAPPE force field ${ }^{56}$ and Lennard-Jones parameters of $\sigma=3.73 \AA$ and $\varepsilon / \mathrm{k}_{\mathrm{B}}=148 \mathrm{~K}$ (no charges considered). The MOF is assumed to be rigid and again described by the universal force field. For the van der Waals interaction a cut-off distance of $12.8 \AA$ is used and periodic boundary conditions are applied. The MUSIC software ${ }^{57}$ is employed for the grand canonical Monte Carlo simulations with $2.5 \cdot 10^{7}$ steps as equilibration period and $2.5 \cdot 10^{7}$ steps as production period. The fugacity coefficients are calculated by the Peng-Robinson equation of state ${ }^{58}$. Previous studies have demonstrated excellent agreement between experiments and simulations using the methodology of the present work ${ }^{59,60}$.

\section{Results and Discussion}

The Poreblazer program ${ }^{61}$ is employed for calculating the geometric surface area (using $\mathrm{N}$ as probe), pore volume (using He as probe), and framework density. The results, given in Table 1 together with the lattice parameters, show a strict trend: The longer the linker the larger are the geometric surface area and pore volume but the smaller is the framework density.

Table 1: Structural properties of the designed tcb-MOFs.

\begin{tabular}{|c|c|c|c|c|}
\hline & $\begin{array}{c}\text { geometric } \\
\text { surface } \\
\text { area }\left(\mathrm{m}^{2} / \mathrm{g}\right)\end{array}$ & $\begin{array}{c}\text { pore } \\
\text { volume } \\
\left(\mathrm{cm}^{3} / \mathrm{g}\right)\end{array}$ & $\begin{array}{c}\text { framework } \\
\text { density } \\
\left(\mathrm{g} / \mathrm{cm}^{3}\right)\end{array}$ & $\begin{array}{c}\text { unit cell parameters: } \\
\mathrm{a}, \mathrm{b}, \mathrm{c}(\AA)\end{array}$ \\
\hline T & 69 & 0.170 & 1.690 & $13.80,5.83,17.16$ \\
\hline B & 321 & 0.441 & 1.219 & $16.07,7.48,20.64$ \\
\hline TT & 1759 & 0.621 & 0.914 & $16.09,8.36,21.55$ \\
\hline TB & 1838 & 0.721 & 0.826 & $16.16,10.30,24.31$ \\
\hline BB & 3040 & 1.094 & 0.641 & $20.64,10.82,28.20$ \\
\hline 2BT & 4445 & 1.808 & 0.444 & $22.03,13.61,32.71$ \\
\hline 3B & 5109 & 1.996 & 0.406 & $22.25,15.67,35.61$ \\
\hline 4T & 6531 & 2.256 & 0.378 & $24.53,11.09,32.00$ \\
\hline 2B2T & 7247 & 2.719 & 0.320 & $26.25,14.81,37.51$ \\
\hline 4B & 7612 & 3.667 & 0.246 & $32.93,16.81,44.38$ \\
\hline 2T3B & 8249 & 4.204 & 0.217 & $31.87,17.96,45.68$ \\
\hline 5B & 7973 & 5.102 & 0.182 & $37.26,20.25,52.31$ \\
\hline
\end{tabular}


(a)

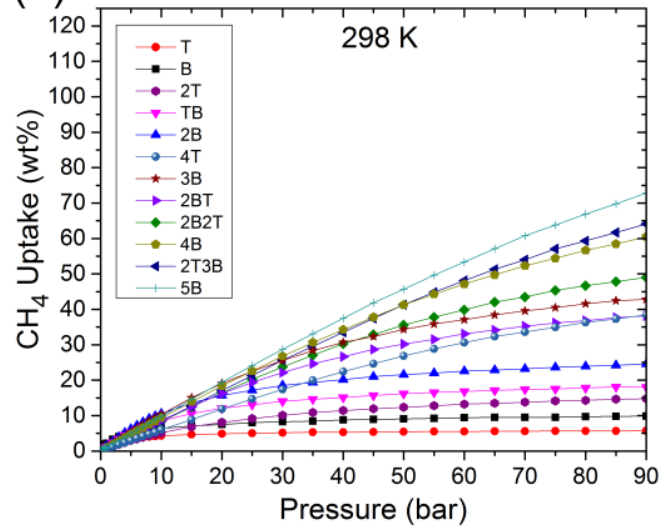

(c)

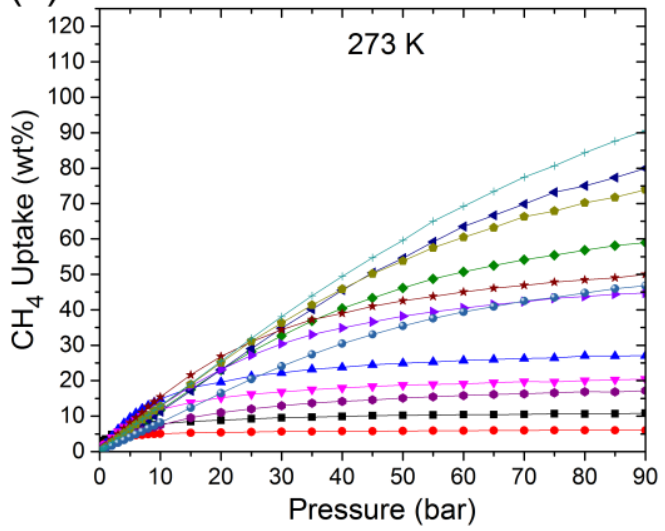

(e)

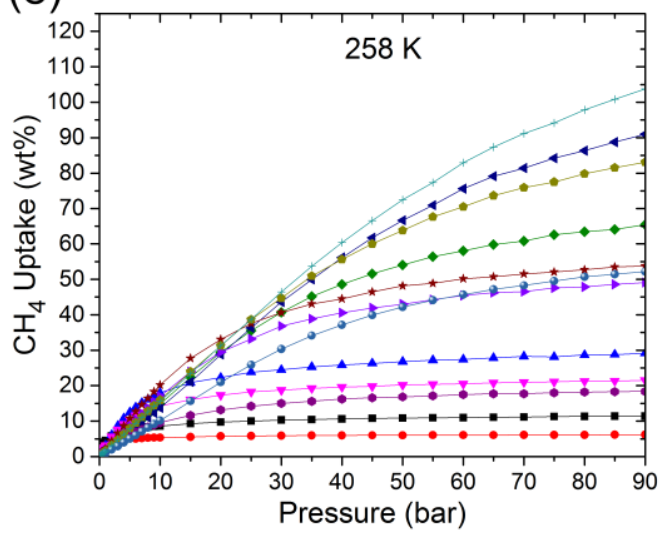

(g)

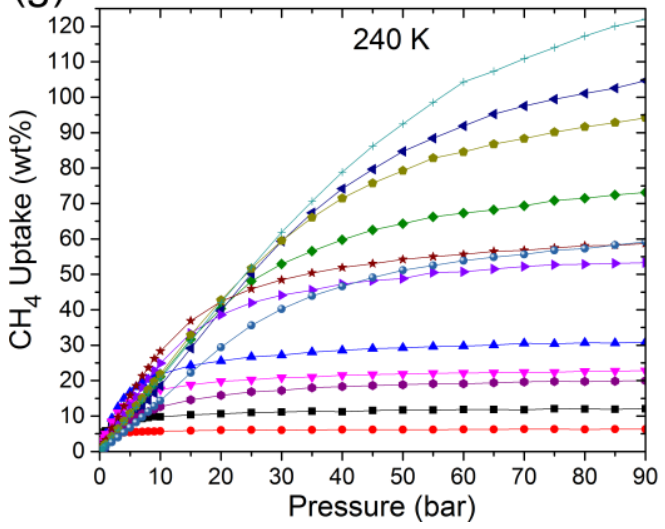

(b)

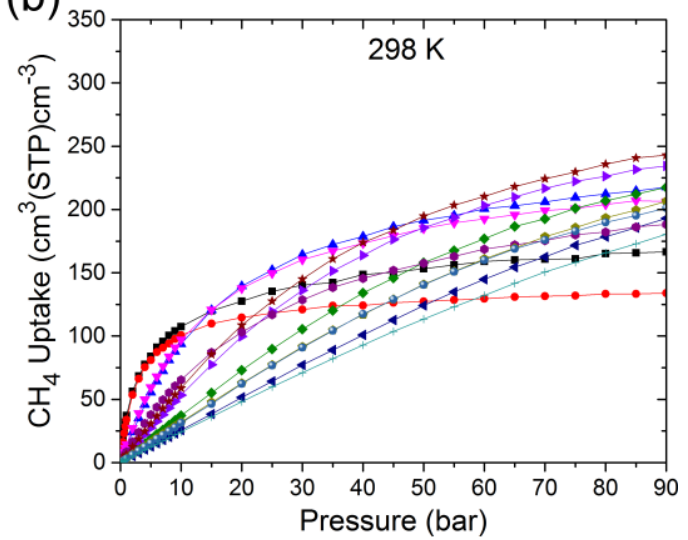

(d)

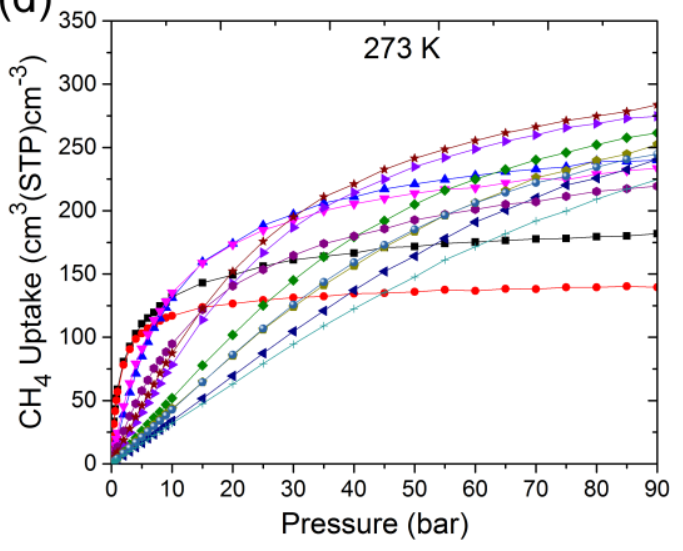

(f)

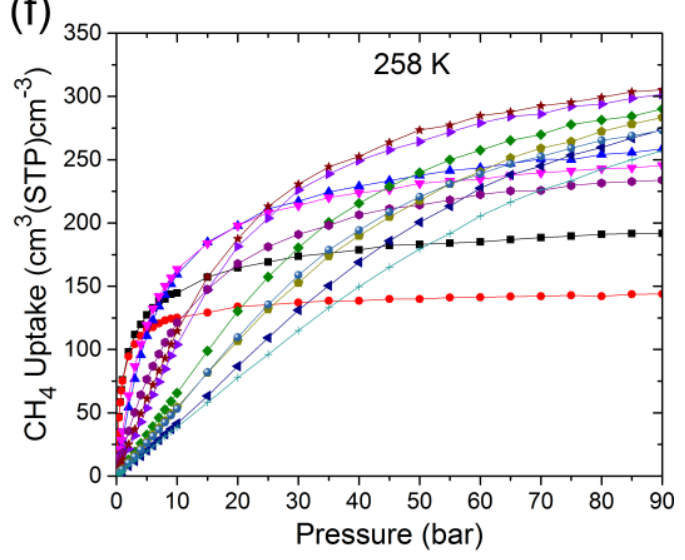

(h)

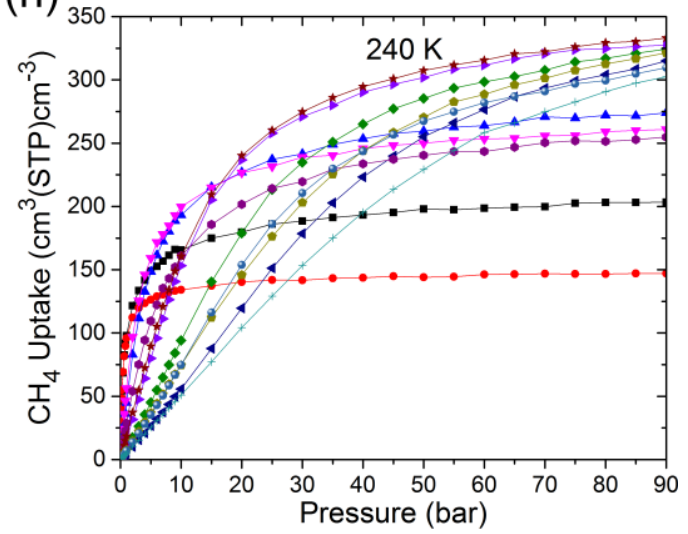

Figure 3. (a,c,e,g) Gravimetric and (b,d,f,h) volumetric sorption isotherms of tcb-MOFs. 
(a)

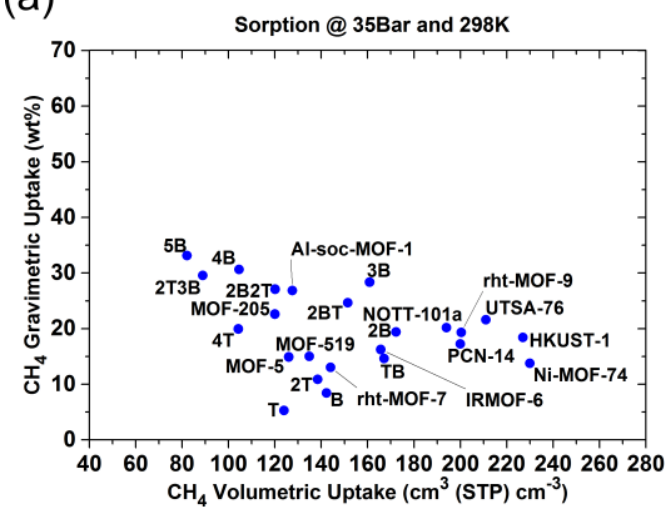

(c)

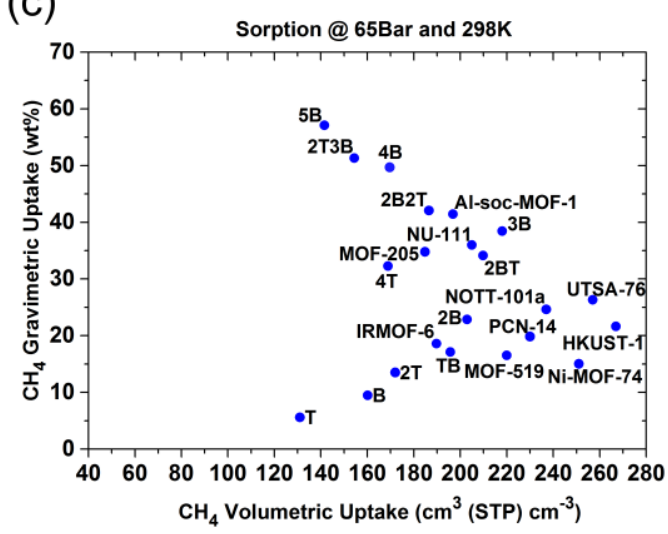

(e)

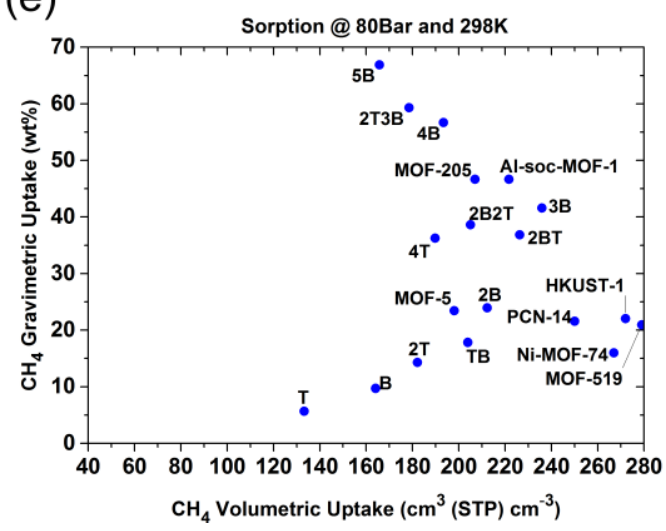

(b)

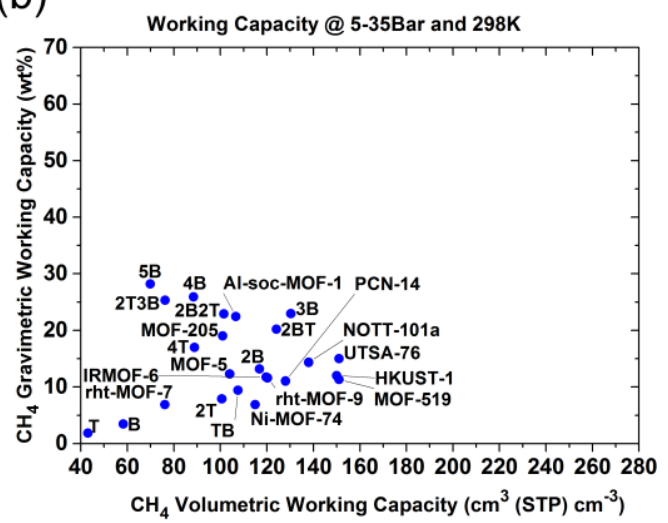

(d)

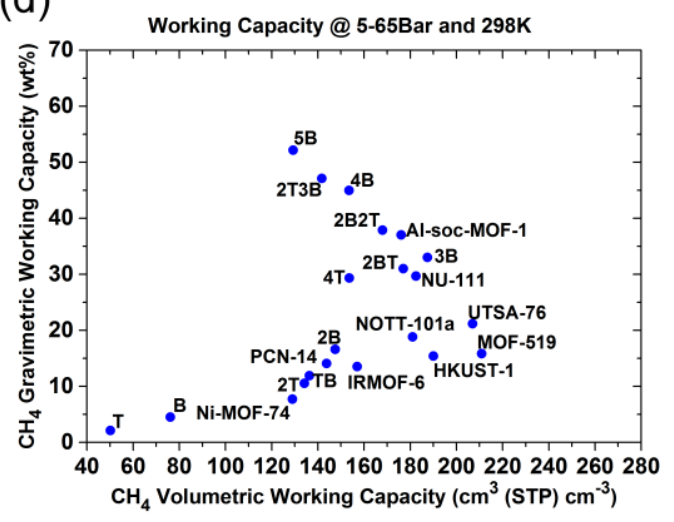

(f)

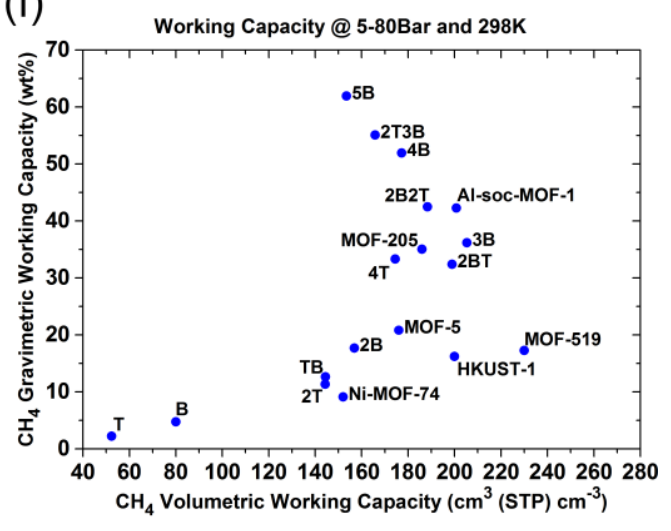

Figure 4. (a,c,e) Total uptake and (b,d,f) working capacity of tcb-MOFs and benchmarking materials from the literature.

Methane sorption isotherms for the family of tcb-MOFs obtained at temperatures of $240 \mathrm{~K}, 258 \mathrm{~K}, 273 \mathrm{~K}$, and $298 \mathrm{~K}$ by grand canonical Monte Carlo simulations for pressure up to 90 bar are shown in Figure 3. The 2BT and 3B MOFs exhibit the highest volumetric total uptakes at high pressure for all temperatures (Figure 3b,d,f,h) and, more importantly, the highest volumetric working capacities at $298 \mathrm{~K}$ for all pressure ranges (Figure $4 \mathrm{~b}, \mathrm{~d}, \mathrm{f})$. The pore diameter is slightly larger than $10 \AA$ (Figure S2) and the framework density turns out to be $0.444 \mathrm{~g} \mathrm{~cm}^{-3}$ and $0.406 \mathrm{~g} \mathrm{~cm}^{-3}$, respectively, which agrees with the finding of Ref. 22 that the highest volumetric working capacity is achieved for pore diameter $\sim 11 \AA$ and framework density $0.4-0.6 \mathrm{~g} \mathrm{~cm}^{-3}$. The methane sorption isotherms of the $\mathbf{T}$, B, TT, TB, and BB MOFs exhibit saturation at comparably low pressures (Figure 3), because of small pore volumes (Table 1), such that no high pressure is required to fill the pores completely. The volumetric total uptake is 
smaller at moderate pressure than expected from the high framework density. High gravimetric and volumetric total uptakes at 5 bar (Figure 3, zoomed view in Figure S1) lead to moderate working capacities at all temperatures studied. The 4T, 2B2T, 4B, 2T3B, and 5B MOFs exhibit very high gravimetric total uptakes, due to large pore volumes and low framework density (Figure 3). Also, because of the low framework density, the volumetric total uptakes are slightly smaller than for the $\mathbf{2 B T}$ and $\mathbf{3 B}$ MOFs. It turns out that the volumetric isotherms of the 2BT, 3B, 4T, 2B2T, 4B, 2T3B, and 5B MOFs approach each other for growing pressure, especially at low temperature ( $240 \mathrm{~K}$ and $258 \mathrm{~K}$ ), when the methane sorption is enhanced. At $298 \mathrm{~K}$ the $\mathbf{5 B}$ MOF shows the highest gravimetric total uptake, reaching $73 \mathrm{wt} \%$, but moderate volumetric total uptake, due to the lowest framework density.

(a)

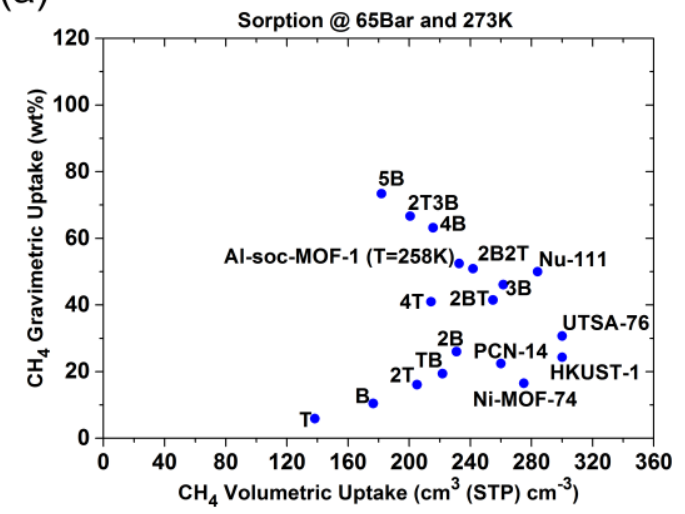

(c)

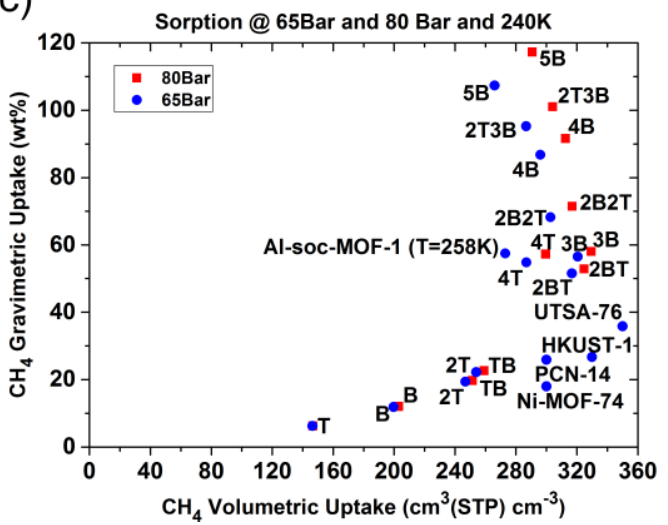

(b)

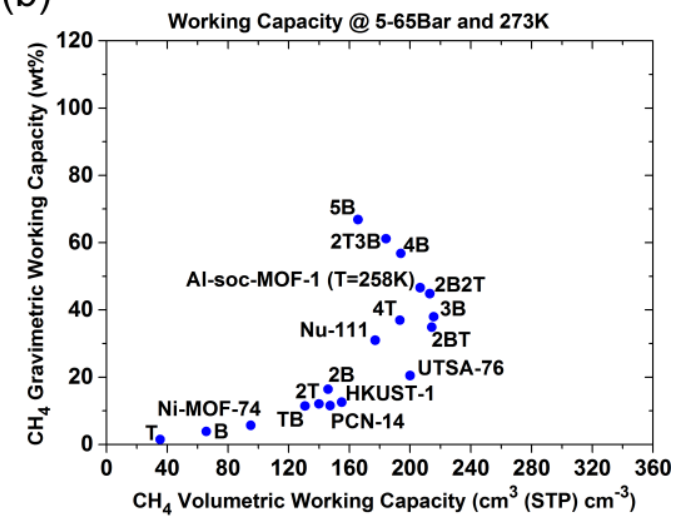

(d)

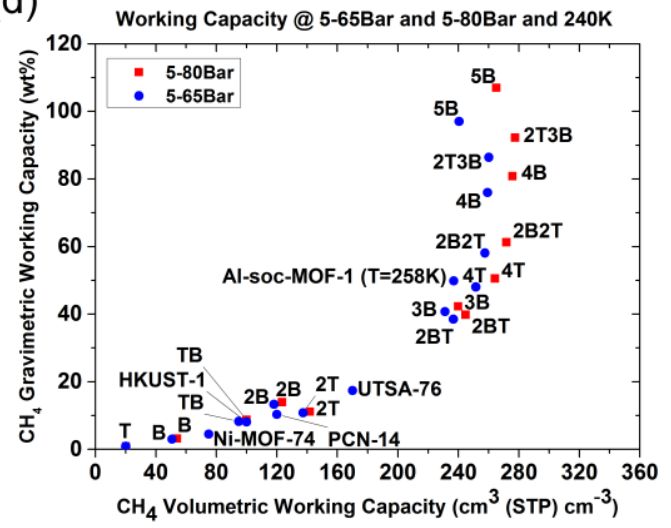

Figure 5. $(a, c)$ Total uptake and $(b, d)$ working capacity of tcb-MOFs and benchmarking materials from the literature.

The total uptakes and working capacities of the designed tcb-MOFs are compared to outstanding existing MOFs with different topologies (rht-MOF-7 ${ }^{62}$, IRMOF-6 ${ }^{63}$, IRMOF-9 ${ }^{63}$, PCN-14 $4^{64,65}$, Ni-MOF-74 ${ }^{64,66,67}$, HKUST-1 ${ }^{64,67,68}$,

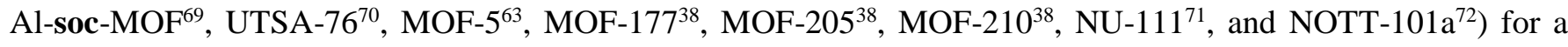
variety of thermodynamic conditions in Figures 4 and 5 to evaluate their suitability for automobile applications. The 4B, 2T3B, and 5B MOFs exceed the gravimetric total uptakes (at 35 bar, 65 bar, and 80 bar) and working capacities (at 5-35 bar, 5-65 bar, and 5-80 bar) of the benchmarking materials. At $298 \mathrm{~K}$ the 5B MOF reaches impressive values of $33.1 \mathrm{wt} \%$ at $35 \mathrm{bar}, 28.2 \mathrm{wt} \%$ at $5-35 \mathrm{bar}, 57.1 \mathrm{wt} \%$ at $65 \mathrm{bar}, 52.2 \mathrm{wt} \%$ at $5-65 \mathrm{bar}, 66.9 \mathrm{wt} \%$ 
at $80 \mathrm{bar}$, and $61.9 \mathrm{wt} \%$ at 5-80 bar, thus satisfying the US DoE targets for automobile applications from the gravimetric point of view. The highest volumetric working capacity of $177.2 \mathrm{~cm}^{3}(\mathrm{STP}) \mathrm{cm}^{-3}$ is obtained for the $4 \mathbf{B}$ MOF at 5-80 bar. The excellent performance of the 4B, 2T3B, and 5B MOFs is explained by the combination of a light structure with a moderate total uptake at 5 bar, see above. The 3B MOF exhibits the most balanced (gravimetric vs. volumetric) total uptake and working capacity in the family of tcb-MOFs at 298 K, see Figure 4. Values of $28.4 \mathrm{wt} \%, 160.9 \mathrm{~cm}^{3}(\mathrm{STP}) \mathrm{cm}^{-3}$ at $35 \mathrm{bar}$ and $23.0 \mathrm{wt} \%, 130.3 \mathrm{~cm}^{3}(\mathrm{STP}) \mathrm{cm}^{-3}$ at $5-35 \mathrm{bar}$ exceed the performance of rht-MOF-7, IRMOF-6, IRMOF-9, PCN-14, Ni-MOF-74, Al-soc-MOF-1, and MOF-205; values of $38.4 \mathrm{wt} \%, 218.0 \mathrm{~cm}^{3}(\mathrm{STP}) \mathrm{cm}^{-3}$ at 65 bar and $33.0 \mathrm{wt} \%, 187.5 \mathrm{~cm}^{3}(\mathrm{STP}) \mathrm{cm}^{-3}$ at 5-65 bar exceed those of IRMOF-6, PCN-14, Ni-MOF-74, HKUST-1, NU-111, and NOTT-101a; values of $41.6 \mathrm{wt} \%, 235.9 \mathrm{~cm}^{3}(\mathrm{STP}) \mathrm{cm}^{-3}$ at $80 \mathrm{bar}$ and $36.2 \mathrm{wt} \%, 205.3 \mathrm{~cm}^{3}(\mathrm{STP}) \mathrm{cm}^{-3}$ at 5-80 bar exceed those of Ni-MOF-74, HKUST-1, MOF-5, and MOF-205.

Figure 5a,b addresses the influence of the temperature by giving results at $273 \mathrm{~K}$, restricted to the total uptake at 65 bar and working capacity at 5-65 bar as for other pressures no data for comparison are available in the literature. The 4B, 2T3B, and 5B MOFs exhibit again the highest gravimetric total uptakes, reaching a maximum of $72.2 \mathrm{wt} \%$ in the case of the 5B MOF, and the $\mathbf{3 B}$ MOF achieves the most balanced performance. In terms of the working capacity, the 2BT, 3B, and 2B2T MOFs outperform the benchmarking materials PCN-14, Ni-MOF-74, HKUST-1, UTSA-76, and NU-111. At further reduced temperature of $240 \mathrm{~K}$ we observe for the $\mathbf{T}$ and $\mathbf{B}$ MOFs saturation of the methane sorption at a pressure of about 5 bar (Figure S1). Thus, the working capacity is very low, especially from the gravimetric point of view (Figure 5c,d). Both the 2BT and $\mathbf{3 B}$ MOFs exhibit balanced total uptakes and working capacities significantly higher than those of the benchmarking materials PCN-14, Ni-MOF-74, HKUST-1, and UTSA-76. The 4T, 2B2T, 4B, 2T3B, and 5B MOFs are characterized by outstanding gravimetric total uptakes (107.4 wt\% in the case of the 5B MOF) and relatively high volumetric uptakes of at least $260.0 \mathrm{~cm}^{3}(\mathrm{STP}) \mathrm{cm}^{-3}$. The volumetric working capacities fall in a narrow range between $240.0 \mathrm{~cm}^{3}(\mathrm{STP}) \mathrm{cm}^{-3}$ and $266.0 \mathrm{~cm}^{3}(\mathrm{STP}) \mathrm{cm}^{-3}$, while the gravimetric working capacities vary strongly from $48.1 \mathrm{wt} \%$ in the case of the $4 \mathrm{~T}$ MOF to $97.1 \mathrm{wt} \%$ in the case of the 5B MOF. Low volumetric total uptakes at 5 bar lead to impressive working capacities outperforming the benchmarking materials PCN-14, Ni-MOF-74, HKUST-1, and UTSA-76. The US DoE targets are almost satisfied from both the gravimetric and volumetric points of view. The comparison to higher pressure in Figure 5c,d shows that larger pore volume enhances both the total uptake and working capacity. In particular, the 4T, 2B2T, 4B, 2T3B, and 5B MOFs satisfy the US DoE targets for automobile applications. The 5B MOF reaches an outstanding gravimetric working capacity of $107.4 \mathrm{wt} \%$. 
(a)

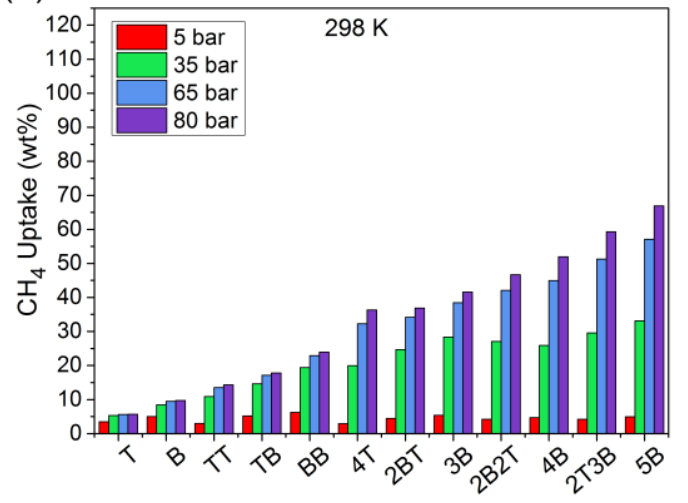

(c)

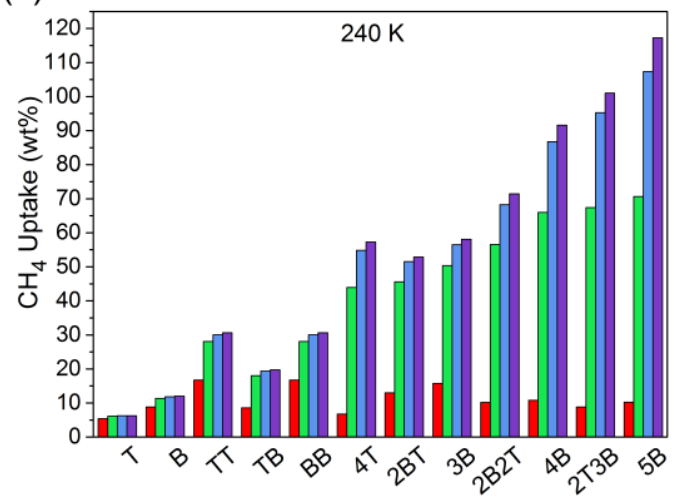

(b)

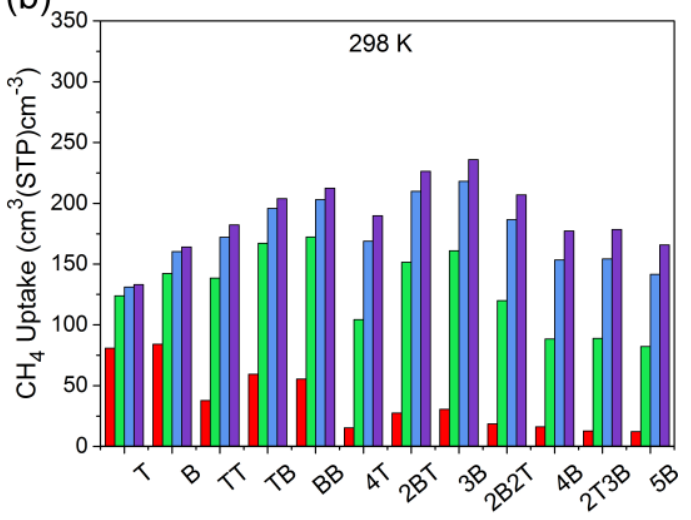

(d)

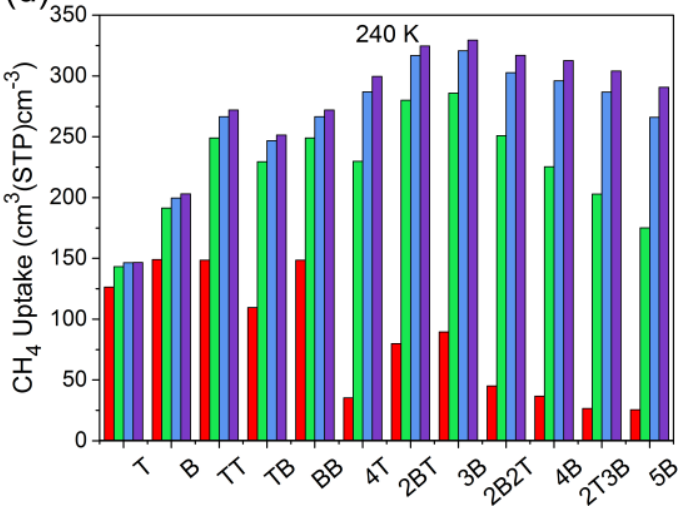

Figure 6. (a,c) Gravimetric and (b,d) volumetric total uptakes of tcb-MOFs at temperatures of $240 \mathrm{~K}$ and $298 \mathrm{~K}$.

Figure 6 illustrates for temperatures of $240 \mathrm{~K}$ and $298 \mathrm{~K}$ (Figure S3 for temperatures of $258 \mathrm{~K}$ and $273 \mathrm{~K}$ ) how much the gravimetric and volumetric total uptakes at 5 bar (red bars) reduce the working capacities. For the $\mathbf{T}$ and B MOFs the impact is massive, because the pore volume is small (Table 1) and the sorption saturates at relatively low pressure. It turns out that the presence of triple bonds in the linker increases the working capacity. While the linkers of the B, TT, and TB MOFs have similar size (implying that the size of the unit cell is also similar), the TT MOF exhibits at $258 \mathrm{~K}, 273 \mathrm{~K}$, and $298 \mathrm{~K}$ the lowest total uptake at 5 bar from both the gravimetric and volumetric points of view. The gravimetric and volumetric total uptakes at $35 \mathrm{bar}, 65 \mathrm{bar}$, and 80 bar increase with the length of the linker (except for $240 \mathrm{~K}$, where the TT MOF shows higher total uptake than the B and TB MOFs). The 4T MOF exhibits at 5 bar one of the smallest total uptakes from both the gravimetric and volumetric points of view at all temperatures (Figure S1). This agrees with previous reports on positive effects of triple bonds on the working capacity of porous materials ${ }^{59,73}$. Moreover, the $4 \mathrm{~T}$ MOF has higher geometric surface area and pore volume but lower framework density than the 2BT and 3B MOFs (see Table 1). The MOFs with the longest linkers and, therefore, lowest framework densities (2B2T, 4B, 2T3B, and 5B) exhibit similar gravimetric total uptakes at 5 bar as the other MOFs, while the volumetric total uptakes are much lower. Figure 6 demonstrates for all MOFs and temperatures that the methane gain from 35 bar to 65 bar is higher than that from 65 bar to 80 bar. For the T, B, TT, TB, and BB MOFs (small pore volume) the methane gain from 65 bar to 80 bar, in fact, is almost negligible, 
while the 2B2T, 4B, 2T3B, and 5B MOFs (large pore volume) exhibit large gains. In addition, the methane gain from 65 bar to 80 bar is smaller at lower temperature, because the pores are saturated at lower pressure.

The dependence of the volumetric uptake on the length of the linker is addressed in Figure 7a, revealing a distinct maximum at each temperature. Interestingly, the maxima follow in good approximation a linear law, which makes it possible to estimate the optimal length of the linker at given temperature. According to Figure $7 \mathrm{~b}$, the maximum volumetric uptake depends almost linearly on the temperature. The isosteric heat of adsorption is calculated from the sorption isotherms at different temperatures. According to Figure 8, the values increase for growing loading. Due to small pores, the values obtained for the $\mathbf{T}$ and $\mathbf{B}$ MOFs exceed those reported for PCN-14, UTSA-20, and HKUST-1 [67]. The 3B and 2BT MOFs exhibit at low loading similar values as Al-soc-MOF [11]. As expected, larger pore volume correlates with lower isosteric heat of adsorption.

(a)

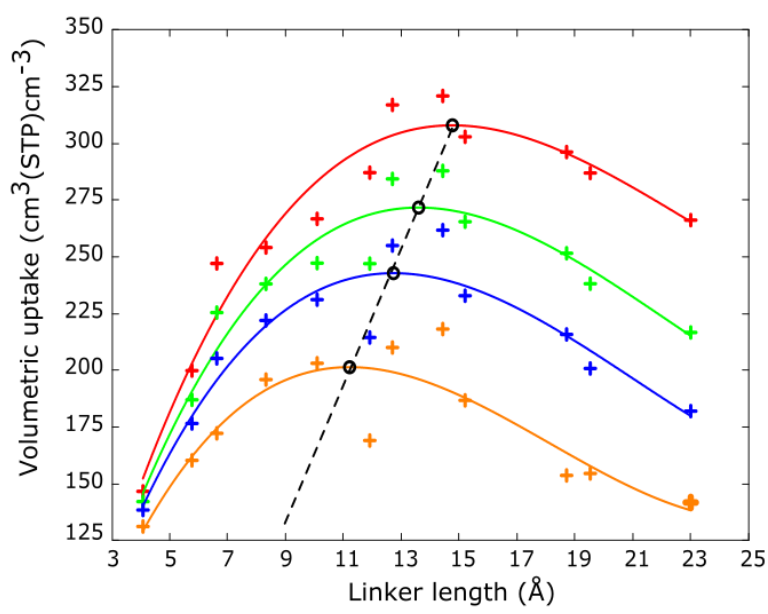

(b)

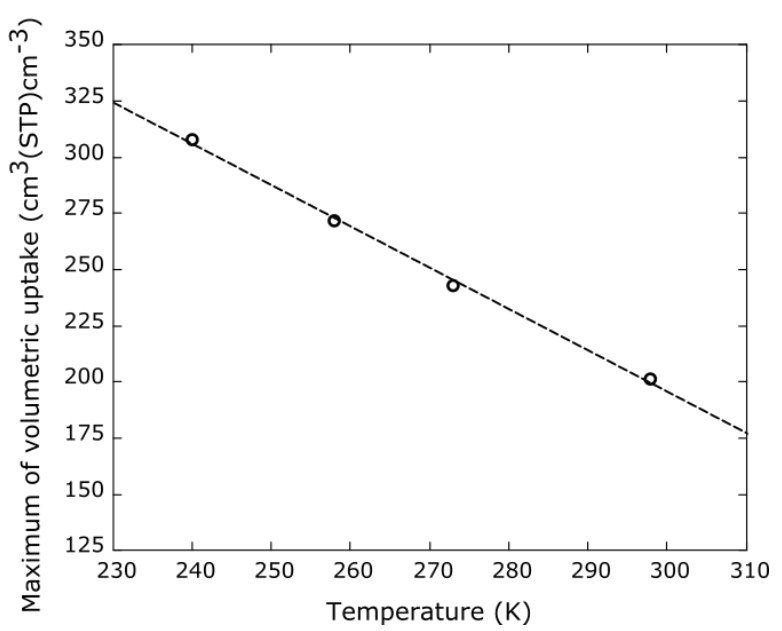

Figure 7. (a) Dependence of the volumetric uptake on the length of the linker at $240 \mathrm{~K}$ (red), $258 \mathrm{~K}$ (green), $273 \mathrm{~K}$ (blue), and $298 \mathrm{~K}$ (orange). The full lines are results of third order polynomial regression at constant temperature.

The maxima (black circles) follow in good approximation a linear law (black dashed line). (b) Maximum volumetric uptake as function of the temperature, demonstrating a linear dependence. 


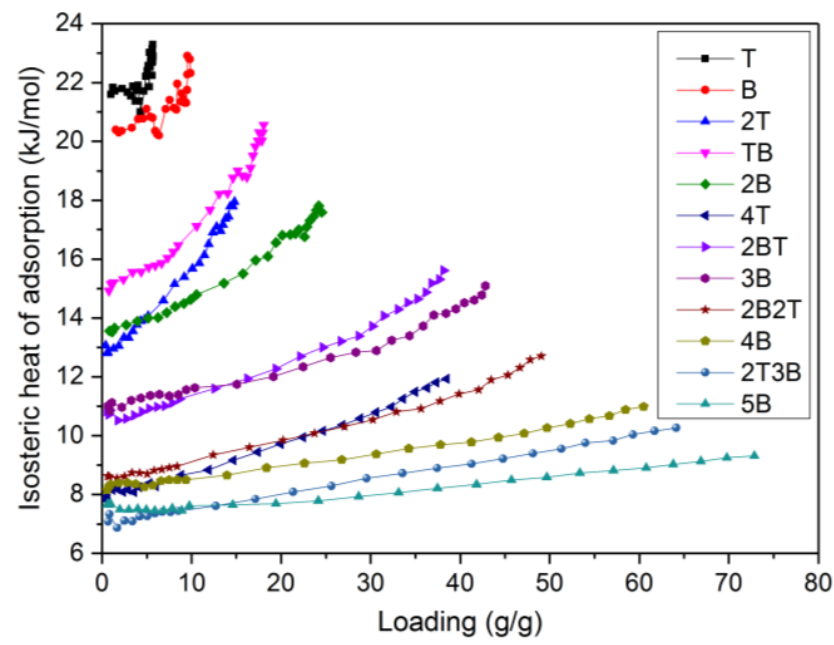

Figure 8. Isosteric heat of adsorption as function of loading.

\section{Conclusions}

A family of MOFs with tcb net topology has been designed by computational means and the properties have been evaluated in detail for identifying candidates that excell in methane storage. Several members of the family exhibit outstanding total uptakes and working capacities. Specifically, the 4T, 2B2T, 4B, 2T3B, and 5B MOFs perform well at low temperature, satisfying the US DoE targets for automobile applications. The highest gravimetric working capacity at $298 \mathrm{~K}$ is observed for the 5B MOF with $52.2 \mathrm{wt} \%$ at 5-65 bar and $61.9 \mathrm{wt} \%$ at 5-80 bar. The 3B MOF exhibits the most balanced (gravimetric vs. volumetric) total uptake and working capacity at $298 \mathrm{~K}$ and all pressures studied. It outperforms many benchmarking materials.

\section{Acknowledgements}

The research reported in this publication was supported by funding from King Abdullah University of Science and Technology (KAUST).

\section{Supporting Information}

Gravimetric and volumetric sorption isotherms of tcb-MOFs at low pressure. Pore size distribution of tcb-MOFs. Gravimetric and volumetric total uptakes of tcb-MOFs at temperatures of $258 \mathrm{~K}$ and $273 \mathrm{~K}$.

\section{References}

(1) Yaghi, O. M.; O'Keeffe, M.; Ockwig, N. W.; Chae, H. K.; Eddaoudi, M.; Kim, J. Reticular Synthesis and the Design of New Materials. Nature. 2003, 423, 705-714.

(2) O'Keeffe, M.; Yaghi, O. M. Deconstructing the Crystal Structures of Metal-Organic Frameworks and Related Materials Into Their Underlying Nets. Chemical Reviews. 2011, 112, 675-702. 
(3) Lee, C. Y.; Farha, O. K.; Hong, B. J.; Sarjeant, A. A.; Nguyen, S. T.; Hupp, J. T. Light-Harvesting MetalOrganic Frameworks (MOFs): Efficient Strut-to-Strut Energy Transfer in Bodipy and Porphyrin-Based MOFs. Journal of the American Chemical Society. 2011, 133, 15858-15861.

(4) Son, H. J.; Jin, S. Y.; Patwardhan, S.; Wezenberg, S. J.; Jeong, N. C.; So, M.; Wilmer, C. E.; Sarjeant, A. A.; Schatz, G. C.; Snurr, R. Q.; Farha, O. K.; Wiederrecht, G. P.; Hupp, J. T. Light-Harvesting and Ultrafast Energy Migration in Porphyrin-Based Metal-Organic Frameworks. Journal of the American Chemical Society. 2013, 135, 862-869.

(5) Sun, C. Y.; Qin, C.; Wang, X. L.; Su, Z. M. Metal-Organic Frameworks as Potential Drug Delivery Systems. Expert Opinion Drug Delivery. 2013, 10, 89-101.

(6) Della Rocca, J.; Liu, D.; Lin, W. Nanoscale Metal-Organic Frameworks for Biomedical Imaging and Drug Delivery. Accounts of Chemical Research. 2011, 44, 957-968.

(7) Lee, J.; Farha, O.K.; Roberts, J.; Scheidt, K. A.; Nguyen, S. T.; Hupp, J. T. Metal-Organic Framework Materials as Catalysts. Chemical Society Reviews 2009, 38, 1450-1459.

(8) Shultz, A. M.; Farha, O. K.; Hupp, J. T.; Nguyen, S. T. A. Catalytically Active, Permanently Microporous MOF with Metalloporphyrin Struts. Journal of the American Chemical Society. 2009, 131, 4204-4205.

(9) Farha, O. K.; Shultz, A. M.; Sarjeant, A. A.; Nguyen, S. T.; Hupp, J. T. Active-Site-Accessible, Porphyrinic Metal-Organic Framework Materials. Journal of the American Chemical Society. 2011, 133, 56525655.

(10) Yang, S. H.; Lin, X.; Blake, A. J.; Walker, G. S.; Hubberstey, P.; Champness, N. R.; Schroder, M. CationInduced Kinetic Trapping and Enhanced Hydrogen Adsorption in a Modulated Anionic Metal-Organic Framework. Nature Chemistry. 2009, 1, 487-493.

(11) Yan, Y.; Telepeni, I.; Yang, S.; Lin, X.; Kockelmann, W.; Dailly, A.; Blake, A. J.; Lewis, W.; Walker, G. S.; Allan, D. R.; Barnett, S. A.; Champness, N. R.; Schröder, M. Metal-Organic Polyhedral Frameworks: High $\mathrm{H}_{2}$ Adsorption Capacities and Neutron Powder Diffraction Studies. Journal of the American Chemical Society. 2010, 132, 4092-4094.

(12) Yang, W.; Greenaway, A.; Lin, X.; Matsuda, R.; Blake, A. J.; Wilson, C.; Lewis, W.; Hubberstey, P.; Kitagawa, S.; Champness, N. R.; Schröder, M. Exceptional Thermal Stability in a Supramolecular Organic Framework: Porosity and Gas Storage. Journal of the American Chemical Society. 2010, 132, 14457-14469.

(13) Yan, Y.; Yang, S. H.; Blake, A. J.; Lewis, W.; Poirier, E.; Barnett, S. A.; Champness, N. R.; Schroder, M. A Mesoporous Metal-Organic Framework Constructed from a Nanosized C-3-Symmetric Linker and [Cu24(Isophthalate)(24)] Cuboctahedra. Chemical Communications. 2011, 47, 9995-9997.

(14) Yang, S. H.; Lin, X.; Lewis, W.; Suyetin, M.; Bichoutskaia, E.; Parker, J. E.; Tang, C. C.; Allan, D. R.; Rizkallah, P. J.; Hubberstey, P.; Champness, N. R.; Thomas, K. M.; Blake, A. J.; Schroder, M. A Partially Interpenetrated Metal-Organic Framework for Selective Hysteretic Sorption of Carbon Dioxide. Nature Materials. 2012, 11, 710-716.

(15) Yang, W. B.; Davies, A. J.; Lin, X.; Suyetin, M.; Matsuda, R.; Blake, A. J.; Wilson, C.; Lewis, W.; Parker, J. E.; Tang, C. C.; George, M. W.; Hubberstey, P.; Kitagawa, S.; Sakamoto, H.; Bichoutskaia, E.; Champness, N. R.; Yang, S. H.; Schroder, M. Selective $\mathrm{CO}_{2}$ Uptake and Inverse $\mathrm{CO}_{2} / \mathrm{C}_{2} \mathrm{H}_{2}$ Selectivity in a Dynamic Bifunctional Metal-Organic Framework. Chemical Science. 2012, 3, 2993-2999. 
(16) Yan, Y.; Suyetin, M.; Bichoutskaia, E.; Blake, A. J.; Allan, D. R.; Barnett, S. A.; Schroder, M. Modulating the Packing of [Cu-24(Isophthalate)(24)] Cuboctahedra in a Triazole-Containing Metal-Organic Polyhedral Framework. Chemical Science. 2013, 4, 1731-1736.

(17) Yang, S.; Liu, L.; Sun, J.; Thomas, K. M.; Davies, A. J.; George, M. W.; Blake, A. J.; Hill, A. H.; Fitch, A. N.; Tang, C. C.; Schröder, M. Irreversible Network Transformation in a Dynamic Porous Host Catalyzed by Sulfur Dioxide. Journal of the American Chemical Society. 2013, 135, 4954-4957.

(18) He, Y.; Zhou, W.; Qian, G.; Chen, B. Methane Storage in Metal-Organic Frameworks. Chemical Society Reviews, 2014, 43, 5657-5678.

(19) He, Y.; Chen, F.; Li, B.; Qian, G.; Zhou, W.; Chen, B. Porous Metal-Organic Frameworks for Fuel Storage. Coordination Chemistry Review, 2017, in press.

(20) Lozano-Castelló, D.; Alcañiz-Monge, J.; de la Casa-Lillo, M. A.; Cazorla-Amorós, D.; Linares-Solano, A. Advances in the Study of Methane Storage in Porous Carbonaceous Materials. Fuel. 2002, 81, 1777-1803.

(21) Wilmer, C. E.; Farha, O. K.; Yildirim, T.; Eryazici, I.; Krungleviciute, V.; Sarjeant, A. A.; Snurr, R. Q.; Hupp, J. T. Gram-Scale, High-Yield Synthesis of a Robust Metal-Organic Framework for Storing Methane and Other Gases. Energy \& Environmental Science. 2013, 6, 1158-1163.

(22) Gándara, F.; Furukawa, H.; Lee, S.; Yaghi, O. M. High Methane Storage Capacity in Aluminum MetalOrganic Frameworks. Journal of the American Chemical Society. 2014, 136, 5271-5274.

(23) https://www.energy.gov/eere/fuelcells/downloads/doe-targets-onboard-hydrogen-storage-systems-lightduty-vehicle (accessed on July $7^{\text {th }}, 2018$ )

(24) Lin, L.-C.; Berger, A. H.; Martin, R. L.; Kim, J.; Swisher, J. A.; Jariwala, K.; Rycroft, C. H.; Bhown, A. S.; Deem, M. W.; Haranczyk, M.; Smit, B. In Silico Screening of Carbon-Capture Materials. Nature Materials. 2012, 11, 633-641.

(25) Simon, C. M.; Kim, J.; Lin, L.-C.; Martin, R. L.; Haranczyk, M.; Smit, B. Optimizing Nanoporous Materials for Gas Storage. Physical Chemistry Chemical Physics. 2014, 16, 5499-5513.

(26) Addicoat, M. A.; Coupry, D. E.; Heine, T. AUTOGRAFS: Automatic Topological Generator for Framework Structures. The Journal of Physical Chemistry A. 2014, 118, 9607-9614.

(27) Martin, R. L.; Simon, C. M.; Smit, B.; Haranczyk, M. In Silico Design of Porous Polymer Networks: HighThroughput Screening for Methane Storage Materials. Journal of the American Chemical Society. 2014, 136, 5006-5022.

(28) Simon, C. M.; Kim, J.; Gomez-Gualdron, D. A.; Camp, J. S.; Chung, Y. G.; Martin, R. L.; Mercado, R.; Deem, M. W.; Gunter, D.; Haranczyk, M.; Sholl, D. S.; Snurr, R. Q.; Smit, B. The Materials Genome in Action: Identifying the Performance Limits for Methane Storage. Energy \& Environmental Science. 2015, 8, 11901199.

(29) Boyd, P. G.; Moosavi, S. M.; Witman, M.; Smit, B. Force-Field Prediction of Materials Properties in Metal-Organic Frameworks. The Journal of Physical Chemistry Letters. 2017, 8, 357-363.

(30) Sarkisov, L.; Martin, R. L.; Haranczyk, M.; Smit, B. On the Flexibility of Metal-Organic Frameworks. Journal of the American Chemical Society. 2014, 136, 2228-2231.

(31) Tam, B.; Yazaydin, O. Design of Electric Field Controlled Molecular Gates Mounted on Metal-Organic Frameworks. Journal of Materials Chemistry A. 2017, 5, 8690-8696.

(32) Wilmer, C. E.; Leaf, M.; Lee, C. Y.; Farha, O. K.; Hauser, B. G.; Hupp, J. T.; Snurr, R. Q. Large-Scale Screening of Hypothetical Metal-Organic Frameworks. Nature Chemistry. 2012, 4, 83-89. 
(33) Fernandez, M.; Boyd, P. G.; Daff, T. D.; Aghaji, M. Z.; Woo, T. K. Rapid and Accurate Machine Learning Recognition of High Performing Metal Organic Frameworks for $\mathrm{CO}_{2}$ Capture. The Journal of Physical Chemistry Letters. 2014, 5, 3056-3060.

(34) Goldsmith, J.; Wong-Foy, A. G.; Cafarella, M. J.; Siegel, D. J. Theoretical Limits of Hydrogen Storage in Metal-Organic Frameworks: Opportunities and Trade-Offs. Chemistry of Materials. 2013, 25, 3373-3382.

(35) Boyd, P. G.; Lee, Y.; Smit, B. Computational Development of the Nanoporous Materials Genome. Nature Reviews Materials. 2017, 2, 17037.

(36) Thornton, A. W.; Simon, C. M.; Kim, J.; Kwon, O.; Deeg, K. S.; Konstas, K.; Pas, S. J.; Hill, M. R.; Winkler, D. A.; Haranczyk, M.; Smit, B. Materials Genome in Action: Identifying the Performance Limits of Physical Hydrogen Storage. Chemistry of Materials. 2017, 29, 2844-2854.

(37) Gómez-Gualdrón, D. A.; Simon, C. M.; Lassman, W.; Chen, D.; Martin, R. L.; Haranczyk, M.; Farha, O. K.; Smit, B.; Snurr, R. Q. Impact of the Strength and Spatial Distribution of Adsorption Sites on Methane Deliverable Capacity in Nanoporous Materials. Chemical Engineering Science. 2017, 159, 18-30.

(38) Alezi, D.; Belmabkhout, Y.; Suyetin, M.; Bhatt, P. M.; Weseliński, Ł. J.; Solovyeva, V.; Adil, K.; Spanopoulos, I.; Trikalitis, P. N.; Emwas, A.-H.; Eddaoudi, M. MOF Crystal Chemistry Paving the Way to Gas Storage Needs: Aluminum-Based SOC-MOF for $\mathrm{CH}_{4}, \mathrm{O}_{2}$, and $\mathrm{CO}_{2}$ Storage. Journal of the American Chemical Society. 2015, 137, 13308-13318.

(39) Blatov, V. A. IUCr CompComm Newsletter. 2006, 7, 4-38.

(40) Tong, M.-L.; Chen, X.-M.; Batten, S. R. A New Self-Penetrating Uniform Net, (8,4) (Or 86), Containing Planar Four-Coordinate Nodes. Journal of the American Chemical Society. 2003, 125, 16170-16171.

(41) Ma, J.-F.; Yang, J.; Zheng, G.-L.; Li; Liu, J.-F. A Porous Supramolecular Architecture from a Copper(II) Coordination Polymer with a 3D Four-Connected 86 Net. Inorganic Chemistry. 2003, 42, 7531-7534.

(42) Kurmoo, M.; Estournès, C.; Oka, Y.; Kumagai, H.; Inoue, K. Knotted Network Consisting of 3-Threads and a Zwitterionic One-Dimensional Polymorphs of Trans-3-(3-Pyridyl)Acrylate of Cobalt and Nickel, $\mathrm{MII}\left(\mathrm{C}_{8} \mathrm{H}_{6} \mathrm{NO}_{2}\right)_{2}\left(\mathrm{H}_{2} \mathrm{O}\right)_{2}$. Inorganic Chemistry. 2005, 44, 217-224.

(43) Dalai, S.; Rana, A.; Bera, M.; Chowdhuri, D. S.; Zangrando, E. 3D Non Porous and Thermally Labile Nickel(II) and Manganese(II) Complexes with Hetero Donor Ligands: Synthesis, X-Ray Single Crystal Structure, Thermal and Luminescent Study. Inorganica Chimica Acta 2010, 363, 1843-1848.

(44) Deng, Z.-P.; Zhang, Z.-Y.; Huo, L.-H.; Ng, S. W.; Zhao, H.; Gao, S. Syntheses, Crystal Structures and Properties of Transition Metal Coordination Polymers Based on Isophthalic Acid and Flexible Bis(Pyridyl) Ligand with Unsymmetrical Spacer: Influence of Metal Cations, Ligand Conformations and Coordination Modes. CrystEngComm. 2012, 14, 6548-6558.

(45) Zhang, L.-N.; Sun, X.-L.; Du, C.-X.; Hou, H.-W. Structural Diversity and Fluorescent Properties of New Metal-Organic Frameworks Constructed from Pamoic Acid and Different N-Donor Ligands. Polyhedron. 2014, 72, 90-95.

(46) Wang, X.-S.; Ma, S.; Rauch, K.; Simmons, J. M.; Yuan, D.; Wang, X.; Yildirim, T.; Cole, W.C.; López, J.J.; Meijere, A.; Zhou, H.-C. Metal Organic Frameworks Based on Double-Bond-Coupled Di-Isophthalate Linkers with High Hydrogen and Methane Uptakes. Chemistry of Materials. 2008, 20, 3145-3152.

(47) O'Keeffe, M.; Peskov, M. A.; Ramsden, S. J.; Yaghi, O. M. The Reticular Chemistry Structure Resource (RCSR) Database of, and Symbols for, Crystal Nets. Accounts of Chemical Research. 2008, 41, 1782-1789. 
(48) Lu, W.; Wei, Z.; Gu, Z.-Y.; Liu, T.-F.; Park, J.; Park, J.; Tian, J.; Zhang, M.; Zhang, Q.; Gentle, T.; Bosch, M.; Zhou, H.-C. Tuning the Structure and Function of Metal-Organic Frameworks Via Linker Design. Chemical Society Reviews. 2014, 43, 5561-5593.

(49) Ji, Y.; Ding, L.; Cheng, Y.; Zhou, H.; Yang, S.; Li, F.; Li, Y. Understanding the Effect of Ligands on $\mathrm{C}_{2} \mathrm{H}_{2}$ Storage and $\mathrm{C}_{2} \mathrm{H}_{2} / \mathrm{CH}_{4}, \mathrm{C}_{2} \mathrm{H}_{2} / \mathrm{CO}_{2}$ Separation in Metal-Organic Frameworks with Open $\mathrm{Cu}(\mathrm{II})$ Sites. Journal of Physical Chemistry C. 2017, 121, 24104-24113.

(50) Lippke, J.; Brosent, B.; von Zons, T.; Virmani, E.; Lilienthal, S.; Preuße, T.; Hülsmann, M.; Schneider, A. M.; Wuttke, S.; Behrens, P.; Godt, A. Expanding the Group of Porous Interpenetrated Zr-Organic Frameworks (PIZOFs) with Linkers of Different Lengths. Inorganic Chemistry. 2017, 56, 748-761.

(51) Materials Studio.

(52) Rappe, A. K.; Casewit, C. J.; Colwell, K. S.; Goddard, W. A.; Skiff, W. M. UFF, A Full Periodic Table Force Field for Molecular Mechanics and Molecular Dynamics Simulations. Journal of the American Chemical Society. 1992, 114, 10024-10035.

(53) José, M. S.; Emilio, A.; Julian, D. G.; Alberto, G.; Javier, J.; Pablo, O.; Daniel, S.-P. The SIESTA Method for Ab Initio Order-N Materials Simulation. Journal of Physics: Condensed Matter. 2002, 14, 2745.

(54) Perdew, J. P.; Burke, K.; Ernzerhof, M. Generalized Gradient Approximation Made Simple. Physical Review Letters. 1996, 77, 3865-3868.

(55) Birch, F. Finite Elastic Strain of Cubic Crystals. Physical Review. 1947, 71, 809-824.

(56) Potoff, J. J.; Siepmann, J. I. Vapor-Liquid Equilibria of Mixtures Containing Alkanes, Carbon Dioxide, and Nitrogen. AIChE Journal. 2001, 47, 1676-1682.

(57) Gupta, A.; Chempath, S.; Sanborn, M. J.; Clark, L. A.; Snurr, R. Q. Object-Oriented Programming Paradigms for Molecular Modeling. Molecular Simulation. 2003, 29, 29-46.

(58) Peng, D.-Y.; Robinson, D. B. A New Two-Constant Equation of State. Industrial \& Engineering Chemistry Fundamentals. 1976, 15, 59-64.

(59) Farha, O. K.; Yazaydın, A. Ö.; Eryazici, I.; Malliakas, C. D.; Hauser, B. G.; Kanatzidis, M. G.; Nguyen, S. T.; Snurr, R. Q.; Hupp, J. T. De Novo Synthesis of a Metal-Organic Framework Material Featuring Ultrahigh Surface Area and Gas Storage Capacities. Nature Chemistry. 2010, 2, 944-948.

(60) Farha, O. K.; Wilmer, C. E.; Eryazici, I.; Hauser, B. G.; Parilla, P. A.; O’Neill, K.; Sarjeant, A. A.; Nguyen, S. T.; Snurr, R. Q.; Hupp, J. T. Designing Higher Surface Area Metal-Organic Frameworks: Are Triple Bonds Better Than Phenyls? Journal of the American Chemical Society. 2012, 134, 9860-9863.

(61) Sarkisov, L.; Harrison, A. Computational Structure Characterisation Tools in Application to Ordered and Disordered Porous Materials. Molecular Simulation. 2011, 37, 1248-1257.

(62) Luebke, R.; Weseliński, Ł. J.; Belmabkhout, Y.; Chen, Z.; Wojtas, Ł.; Eddaoudi, M. Microporous Heptazine Functionalized (3,24)-Connected RHT-Metal-Organic Framework: Synthesis, Structure, and Gas Sorption Analysis. Crystal Growth \& Design. 2014, 14, 414-418.

(63) Eddaoudi, M.; Kim, J.; Rosi, N.; Vodak, D.; Wachter, J.; O'Keeffe, M.; Yaghi, O. M. Systematic Design of Pore Size and Functionality in Isoreticular MOFS and Their Application in Methane Storage. Science. 2002, 295, 469-472.

(64) Mason, J. A.; Veenstra, M.; Long, J. R. Evaluating Metal-Organic Frameworks for Natural Gas Storage. Chemical Science. 2014, 5, 32-51. 
(65) Ma, S.; Sun, D.; Simmons, J. M.; Collier, C. D.; Yuan, D.; Zhou, H.-C. Metal-Organic Framework from an Anthracene Derivative Containing Nanoscopic Cages Exhibiting High Methane Uptake. Journal of the American Chemical Society. 2008, 130, 1012-1016.

(66) Rosi, N. L.; Kim, J.; Eddaoudi, M.; Chen, B.; O'Keeffe, M.; Yaghi, O. M. Rod Packings and MetalOrganic Frameworks Constructed from Rod-Shaped Secondary Building Units. Journal of the American Chemical Society. 2005, 127, 1504-1518.

(67) Peng, Y.; Krungleviciute, V.; Eryazici, I.; Hupp, J. T.; Farha, O. K.; Yildirim, T. Methane Storage in Metal-Organic Frameworks: Current Records, Surprise Findings, and Challenges. Journal of the American Chemical Society. 2013, 135, 11887-11894.

(68) Chui, S. S.-Y.; Lo, S. M.-F.; Charmant, J. P. H.; Orpen, A. G.; Williams, I. D. A. Chemically Functionalizable Nanoporous Material. Science. 1999, 283, 1148-1150.

(69) Li, B.; Wen, H.-M.; Wang, H.; Wu, H.; Tyagi, M.; Yildirim, T.; Zhou, W.; Chen, B. A Porous MetalOrganic Framework with Dynamic Pyrimidine Groups Exhibiting Record High Methane Storage Working Capacity. Journal of the American Chemical Society. 2014, 136, 6207-6210.

(70) Furukawa, H.; Ko, N.; Go, Y. B.; Aratani, N.; Choi, S. B.; Choi, E.; Yazaydin, A. Ö.; Snurr, R. Q.; O'Keeffe, M.; Kim, J.; Yaghi, O. M. Ultrahigh Porosity in Metal-Organic Frameworks. Science. 2010, 329, 424-428.

(71) Peng, Y.; Srinivas, G.; Wilmer, C. E.; Eryazici, I.; Snurr, R. Q.; Hupp, J. T.; Yildirim, T.; Farha, O. K. Simultaneously High Gravimetric and Volumetric Methane Uptake Characteristics of the Metal-Organic Framework NU-111. Chemical Communications. 2013, 49, 2992-2994.

(72) He, Y.; Zhou, W.; Yildirim, T.; Chen, B. A Series of Metal-Organic Frameworks with High Methane Uptake and an Empirical Equation For Predicting Methane Storage Capacity. Energy \& Environmental Science. 2013, 6, 2735-2744.

(73) Gómez-Gualdrón, D. A.; Gutov, O. V.; Krungleviciute, V.; Borah, B.; Mondloch, J. E.; Hupp, J. T.; Yildirim, T.; Farha, O. K.; Snurr, R. Q. Computational Design of Metal-Organic Frameworks Based on Stable Zirconium Building Units for Storage and Delivery of Methane. Chemistry of Materials. 2014, 26, 5632-5639. 
Table of Contents Graphic
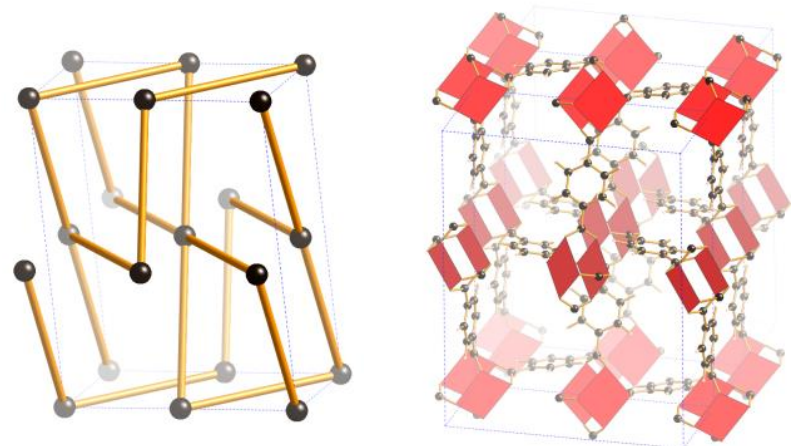